\title{
Development of a highly sensitive real-time one step RT-PCR combined complementary locked primer technology and conjugated minor groove binder probe
}

JiYoung Hong ${ }^{1,3}$, Byunghak Kang ${ }^{1}$, Ahyoun Kim¹, Seoyeon Hwang ${ }^{1,4}$, Jinhee Ahn', Sunhwa Lee ${ }^{1}$, Jonghyen Kim², Jae-Hak Park ${ }^{3}$ and Doo-Sung Cheon ${ }^{1 *}$

\begin{abstract}
Background: Enterovirus (EV) infections are commonly associated with encephalitis and meningitis. Detection of enteroviral RNA in clinical specimens has been demonstrated to improve the management of patients, by ruling out other causes of disease.

Method: To develop a sensitive and reliable assay for routine laboratory diagnosis, we developed a real-time one step reverse transcription polymerase chain reaction (RT-PCR) assay with minor groove binder probes and primers modified with complementary locked primer technology (TMC-PCR). We checked the sensitivity of the developed assay by comparing it to a previously published TaqMan probe real-time one-step RT-PCR (TTN-PCR) procedure using enteroviral isolates, Enterovirus Proficiency panels from Quality Control on Molecular Diagnostics (QCMD2007), and clinical specimens from patients with suspected EV infections.

Results: One hundred clinical specimens from 158 suspected viral meningitis cases were determined to be positive by the TMC-PCR assay (63.29\%), whereas only 60 were found to be positive by the TTN-PCR assay (37.97\%). The positive and negative agreements between the TMC-PCR and TTN-PCR assays were 100\% and 59.2\%, respectively.

Conclusion: This data suggest that the TMC-PCR assay may be suitable for routine diagnostic screening from patient suspected EV infection.
\end{abstract}

Keywords: Aseptic meningitis, Real-time one step RT-PCR, CLP, MGB probe

\section{Background}

Enteroviruses (EVs) are among the most common and important viruses infecting humans. EVs are associated with diverse clinical syndromes, ranging from mild febrile illness to severe central nervous system diseases, such as aseptic meningitis and encephalitis, potentially leading to paralysis $[1,2]$. Neonates and young children are at the greatest risk of developing severe, and occasionally fatal, enteroviral infections $[3,4]$. Serotypes of EVs have traditionally been classified into echoviruses, coxsackieviruses,

\footnotetext{
* Correspondence: cheonds@hanmail.net

'Division of Enteric and Hepatitis Viruses, Center for Infectious Diseases, National Institute of Health, Korea Center for Disease Control and Prevention, Chungcheongbuk-do, 363-951, Korea

Full list of author information is available at the end of the article
}

groups A and B, and polioviruses [5]. Currently, EV subtypes are divided into five species (human enteroviruses $[\mathrm{HEV}] \mathrm{A}, \mathrm{B}, \mathrm{C}, \mathrm{D}$, and poliovirus) with differing molecular and biological characteristics [6]. Laboratory methods used for the diagnosis of enteroviral infection have changed substantially over time [7-9]. Initially, EVs were detected exclusively by cell culture and identified by neutralization [10]. In the mid-1990s, polymerase chain reaction (PCR) methods that can detect all EVs were introduced and have supplanted cell culture in many diagnostic laboratories [11-13]. Cell culture methods for the detection of EVs are time-consuming, requiring, on average, 7-14 days for identification. Also, most coxsackievirus group A viruses do not adapt to cells as well as other EVs [14]. Although cell culture remains the gold standard for 
the identification of EVs in suspected patients, molecular methods such as reverse transcription PCR (RT-PCR), real-time RT-PCR, and nucleic acid sequence-based amplification offer more sensitive, specific, and rapid results [15-17]. However diagnosis by RT-PCR also has problems, including contamination from post-reaction handling and variation in results depending on laboratory staff. Several groups have described real-time RT-PCR methods for the detection of EVs in cerebrospinal fluid (CSF) [18-23].

This study was developed and validated a rapid, sensitive, and reliable real-time RT-PCR assay for the routine identification of EVs using the TaqMan minor groove binder (MGB) format combined complementary locked primer (CLP) technology [24]: the TMC-PCR assay $[25,26]$. After experiments to evaluate its analytical sensitivity, specificity, and reproducibility, it was used with clinical specimens from patients and the results were compared to those using a previously published TaqMan probe real-time one step RT-PCR (TTN-PCR [23]) assay.

\section{Methods}

\section{Viruses and Controls}

Five reference strains belonging to distinct genogroups [enterovirus 71 (EV71), coxsackievirus B2 (CVB2), echo 30 (E30), coxsackievirus A24 (CVA24), and poliovirus type 1 (P1)] were obtained from the American Type Culture Collection (ATCC) and were used to optimize TTN-PCR conditions and to evaluate analytical performance. Infectivity of viruses was assayed in microplates in serial 10-fold dilutions (from $10^{-4}$ to $10^{-10}$ ) with four wells per dilution. TCID $_{50}$ titers were calculated according to the Kärber method [27]. Enteroviral isolates including 25 serotypes (12 echovirus (E1, 3, 5-7, 9, 13, 14, 16, 1, 25 and 30), four coxsackievirus A (CVA 10, 16, 22 and 24), six coxsackievirus B (CVB 1-6), poliovirus type 1 (P1) and two new enterovirus (EV71 and 74) circulating between 1997 and 2005 in Korea were used to evaluate the reactivity of the assay to various serotypes of EVs. Enterovirus Proficiency panels from Quality Control on Molecular diagnostics (QCMD-2007) were also included to compare results from both assays.

\section{Clinical samples}

In total, 158 clinical specimens, collected from patients with suspected viral meningitis between June and September 2008, were included for evaluation with both real-time PCR assays.

\section{Extraction of viral RNA}

RNA was extracted from $150 \mu \mathrm{L}$ samples with the GM Viral Nucleic Acid Extraction Kit (GreenMate Biotech Corp, Korea), according to the manufacturer's protocol using automated machines for liquid handling (Tecan,
Switzerland). The GM Viral Nucleic Acid Extraction Kit uses a silica-based extraction method [28]. RNA was then recovered in $50 \mu \mathrm{L}$ of nuclease-free water. It was used immediately or stored at $-70^{\circ} \mathrm{C}$.

\section{Primers and probe}

The TMC-PCR assay for detecting EVs is based on TaqMan technology. However, to improve the sensitivity and specificity for all enteroviruses, the primers and probe described by Verstrepen et al. was modified [23]. The primer pair was modified with CLP technology (iNtRON Biotechnology, Korea); the forward and reverse primers had 5-mer nucleotides added in complementary sequences at their 5'-ends. To develop the TMC-PCR, the TaqMan probe was modified to an MGB-conjugated hybridization probe and was shorter than that described by Verstrepen et al. [23]. The TMC-PCR used two primers: NCR-cF and NCR-cR that described by Hong J et al. [24]. The TaqMan MGB probe, referred to TMP, was: FAM5'-CCGACTACTTTGGGTGTC-3'MGB-NFQ (positions 541-558 of the CVB2 sequence; GenBank accession number EF174469). It contains the reporter 6carboxyfluorescein (FAM) and the non-fluorescent quencher (NFQ) dye.

\section{Real-time One Step RT-PCR}

TMC-PCR assay was performed using an ABI Prism 7900HT sequence detection system (Applied Biosystems). Viral RNA was amplified in $25 \mu \mathrm{L}$ reactions using RT-PCR master mix (AgPath-ID one-step RT-PCR Kit; Ambion, CA). Reactions were incubated at $45^{\circ} \mathrm{C}$ for $15 \mathrm{~min}$, and then at $95^{\circ} \mathrm{C}$ for $10 \mathrm{~min}$, followed by 45 cycles of $95^{\circ} \mathrm{C}$ for $15 \mathrm{~s}$ and $60^{\circ} \mathrm{C}$ for $40 \mathrm{~s}$.

\section{Results}

\section{Limits of detection and reproducibility}

To determine the detection limit of the TMC-PCR and TTN-PCR assays, serial dilutions of five reference strains belonging to distinct serotypes (EV71, CVB2, E30, CVA24, and P1) were tested. The highest positive dilution of CVB2, $0.5 \mathrm{TCID}_{50} / \mathrm{mL}$, corresponded to a Ct of 35.6 , whereas the lowest dilution, $1 \times 10^{7} \mathrm{TCID}_{50} / \mathrm{mL}$, corresponded to a $\mathrm{Ct}$ of 8.38 of P1. Each of the titrated viruses was a member of a major EV group. The minimum detectable amount of enteroviral RNA was equivalent to $0.01 \mathrm{TCID}_{50}$ in CVA24. The detection limit of the end point was the same in the TMC-PCR and TTN-PCR assays (data not shown).

Reproducibility was tested by analyzing a titrated P1 virus at least three times on different days (Table 1 ). In the TMC-PCR assay, the Ct mean values of the $10^{-2}\left(10^{5}\right.$ $\left.\mathrm{TCID}_{50} / \mathrm{mL}\right)$ and $10^{-3}\left(10^{4} \mathrm{TCID}_{50} / \mathrm{mL}\right)$ RNA extracts, performed in duplicate in three different runs, were 21.55 and 
Table 1 Intra- and inter-assay reproducibility of the EV MGB/CLP (TMC-PCR) and TAMRA/NonCLP real time RT-PCR (TTN-PCR)

\begin{tabular}{|c|c|c|c|c|c|c|c|c|}
\hline \multirow[b]{3}{*}{ Assay } & \multicolumn{4}{|c|}{ Intra assay $^{a}$} & \multicolumn{4}{|c|}{ Inter assay $^{b}$} \\
\hline & \multicolumn{2}{|c|}{$10^{5} \mathrm{TCID}_{50} / \mathrm{mL}$} & \multicolumn{2}{|c|}{$10^{4} \mathrm{TCID}_{50} / \mathrm{mL}$} & \multicolumn{2}{|c|}{$100 \mathrm{TCID}_{50} / \mathrm{mL}$} & \multicolumn{2}{|c|}{$10 \mathrm{TCID}_{50} / \mathrm{mL}$} \\
\hline & Mean $^{c}$ & S.D ${ }^{d}$ & Mean $^{c}$ & S.D $\mathrm{D}^{d}$ & Mean $^{c}$ & S.D ${ }^{d}$ & Mean $^{c}$ & S.D ${ }^{d}$ \\
\hline TTN-PCR $^{e}$ & 21.22 & 0.24 & 24.82 & 0.16 & 29.05 & 1.89 & 32.62 & 2.09 \\
\hline TMC-PCR $^{f}$ & 21.55 & 0.08 & 25.02 & 0.07 & 30.65 & 0.86 & 33.95 & 0.80 \\
\hline
\end{tabular}

${ }^{a}$ Each $\mathrm{Ct}$ value was determined from eight replicates within a assay

${ }^{b}$ Assays were performed three times on different days in an independent manner

${ }^{c}$ Mean of threshold cycle $(\mathrm{Ct})$ value

${ }^{d}$ Standard deviation

e TAMRA/NonCLP real time RT-PCR assay

${ }^{f} \mathrm{MGB} / \mathrm{CLP}$ real time RT-PCR assay.

25.02, respectively, with intra-assay standard deviations of 0.08 and 0.07 , respectively. The $\mathrm{Ct}$ mean values of the $10^{-5}$ $\left(100 \mathrm{TCID}_{50} / \mathrm{mL}\right)$ and $10^{-6}\left(10 \mathrm{TCID}_{50} / \mathrm{mL}\right)$ RNA extracts, performed in duplicate in three different runs, were 30.65 and 33.95, respectively, with inter-assay standard deviations of 0.86 and 0.80 , respectively.

In the TTN-PCR assay, the Ct mean values of the $10^{-2}$ $\left(10^{5} \mathrm{TCID}_{50} / \mathrm{mL}\right)$ and $10^{-3}\left(10^{4} \mathrm{TCID}_{50} / \mathrm{mL}\right)$ RNA extracts, performed in duplicate in three different runs, were 21.22 and 24.82, respectively, with intra-assay standard deviations of 0.24 and 0.16 respectively. The $\mathrm{Ct}$ mean values of the $10^{-5}\left(100 \mathrm{TCID}_{50} / \mathrm{mL}\right)$ and $10^{-6}(10$ $\mathrm{TCID}_{50} / \mathrm{mL}$ ) RNA extracts, performed in duplicate in three different runs, were 29.05 and 32.62, respectively, with inter-assay standard deviations of 1.89 and 2.09, respectively.

\section{Analytical sensitivity and specificity}

All clinical isolates of 25 serotypes circulating between 1997 and 2007 in Korea of EVs could be detected and there was no inconsistency between the qualitative results generated by the two assays (TMC-PCR and TTN-PCR). This confirms that the modifications to the primers and probes did not affect the detectable reaction to various EV serotypes (in other words, panenterovirus).

From the results for the 12 proficiency panels (EV07) from QCMD (Glasgow, Scotland), including various titers of coxsackievirus B3 (CVB3), echovirus 11 (E11), enterovirus 71 (EV71), echovirus 30 (E30), and poliovirus type 3 (P3), could be detected the genomes of EVs, including three serotypes with different detection limits, depending on the assay used (Table 2). In the each case of CVB3 (EV07-07 vs. EV07-12), E11 (EV07-03 vs. EV07-04) and E30 (EV07-08 vs. EV07-09), at a 10-fold lower viral titer than the panel, TMC-PCR assay produced a positive result, whereas TTN-PCR assay produced a negative. Parechovirus type 3 in sample EV07-02 and EV07-11 was not detected by either assay, confirming that both assays were specific to EVs.

Table 2 Result with Enterovirus real time quality control panels

\begin{tabular}{|c|c|c|c|c|}
\hline Panel no. & Serotype & $\mathrm{TCID}_{50} / 0.05 \mathrm{~mL}^{a}$ & TMC-PCR $^{b}$ & TTN-PCR \\
\hline EV07-01 & Coxsackievirus B3 & 50 & $p^{d}$ & $p^{d}$ \\
\hline EV07-02 & Parechovirus 3 & 5.6 & $\mathrm{~N}^{e}$ & $\mathrm{~N}^{e}$ \\
\hline EV07-03 & Echovirus 11 & 0.13 & $\mathrm{P}^{d}$ & $\mathrm{~N}^{e}$ \\
\hline EV07-04 & Echovirus 11 & 1.3 & $\mathrm{p}^{d}$ & $\mathrm{p}^{d}$ \\
\hline EV07-05 & Negative & 0 & $\mathrm{~N}^{e}$ & $\mathrm{~N}^{e}$ \\
\hline EV07-06 & Enterovirus 71 & 2.8 & $\mathrm{p}^{d}$ & $\mathrm{P}^{d}$ \\
\hline EV07-07 & Coxsackievirus B3 & 5 & $\mathrm{p}^{d}$ & $\mathrm{p}^{d}$ \\
\hline EV07-08 & Echovirus 30 & 2.5 & $\mathrm{p}^{d}$ & $\mathrm{p}^{d}$ \\
\hline EV07-09 & Echovirus 30 & 0.25 & $\mathrm{P}^{d}$ & $\mathrm{~N}^{e}$ \\
\hline EV07-10 & Poliovirus type 3 & 0.063 & $\mathrm{P}^{d}$ & $\mathrm{P}^{d}$ \\
\hline EV07-11 & Parechovirus 3 & 0.056 & $\mathrm{~N}^{e}$ & $\mathrm{~N}^{e}$ \\
\hline EV07-12 & Coxsackievirus B3 & 0.5 & $\mathrm{p}^{d}$ & $\mathrm{~N}^{e}$ \\
\hline
\end{tabular}

\footnotetext{
${ }^{a}$ tissue culture infectious dose per $0.05 \mathrm{~mL}$

${ }^{b} \mathrm{MGB} / \mathrm{CLP}$ real time RT-PCR assay

c TAMRA/NonCLP real time RT-PCR assay

${ }^{d}$ positive results

${ }^{e}$ negative results.
} 


\section{Comparison of TMC-PCR and TTN-PCR assays with clinical specimens}

A total of 158 clinical specimens from patients diagnosed with meningitis were evaluated. Sixty were positive in both TMC-PCR and TTN-PCR assays, whereas 40 in total 158 samples were positive only in the TMC-PCR assay. The results were consistent number of negative results in both case 58/98 (Table 3). The clinical specimens consisted of 102 CSF, 48 stool, and 8 throat swab samples. To investigate assay results among different types of specimens, the TMC-PCR and TTN-PCR assays were compared using the 102 CSF samples tested; 62 and 29 samples were positive using the TMC-PCR and TTNPCR assays, respectively. Thirty-six of the 48 stool samples were positive using the TMC-PCR assay and 29 using the TTN-PCR assay. Of the throat swab samples, 2 of 8 were positive by both assays.

In all specimens, the positive and negative agreements of the TTN-PCR assay and the TMC-PCR assay were $100 \%(60 / 60)$ and $59.2 \%(58 / 98)$, respectively. In CSF specimens, the positive and negative agreements of the TTN-PCR assay and the TMC-PCR assay were $100 \%$ $(29 / 29)$ and $54.79 \%(40 / 73)$, respectively. In stool specimens, the positive and negative agreements of the TTNPCR assay and the TMC-PCR assay were 100\% (29/29) and $63.16 \%(12 / 19)$, respectively. In throat swab specimens, the positive and negative agreements of the TTNPCR assay and the TMC-PCR assay were $100 \%(2 / 2)$ and $100 \%(6 / 6)$, respectively.

\section{Discussion}

Several groups have developed and demonstrated molecular diagnostic methods that are highly sensitive, specific, simple, and reproducible. In the field of virology, real-time RT-PCR has become a standard diagnostic method because of its rapid turnaround time, relatively low risk of contamination, and ease of use [19,29].

This study modified a TTN-PCR published method [23] and compared it to our modified assay, TMC-PCR, for use as a routine diagnostic assay. TMC-PCR assay detected the same region of the $5^{\prime}-\mathrm{NCR}$ as the traditional
Verstrepen amplicon. The primers used in this assay combined previously reported CLP technology [24], a probe modified at the 5 -terminal by $\mathrm{MGB}$, and a 3'-terminal NFQ. These probes provided lower backgrounds and a higher signal-to-noise ratio than other hybridization probes [30]. MGB allows the design and use of shorter probes, while maintaining a high melting temperature, which may be an advantage in designing probes for small conserved regions $[25,26]$.

The results of the modified primers and probe using the 2007 QCMD panel were compared. TMC-PCR assay detected all EVs in the panels, except parechovirus. However, the TTN-PCR assay could not detect some EVs, such as echovirus 11 and coxsackievirus B3, in the 2007 panel. These false negative results were in low viral titer samples (Table 1). To test TMC-PCR for EVs, EV71, CVB2, E30, CVA24, and P1, as example EV serotypes, were used to determine the dynamic range, to optimize real-time PCR conditions, and to evaluate analytical performance. The detection limits for EV in both assays were similar (data not shown). However, standard deviations (SDs) of the intra-assay and inter-assay reproducibility of the TMC-PCR and TTN-PCR assays were different, particularly at low viral dilutions (Table 2). Thus, TMC-PCR had better assay reproducibility.

To examine the analytical performances of the TMCPCR and TTN-PCR assays, a prospective study on clinical samples was conducted. In 158 clinical samples from patients with aseptic meningitis, enterovirus was detected in 100 of 158 samples by TMC-PCR and 60 of 158 samples by TTN-PCR. A comparison of the TMCPCR and TTN-PCR assays revealed 40 discrepant samples (Table 3), 33 (82.5\%) of which were CSF specimens. When separately analyzed using CSF specimens, the positive and negative agreements between TMC-PCR and TTN-PCR were $100 \%$ and $54.79 \%$, respectively. Then the GeneXpert Enterovirus Assay (GXEA; Cepheid, Sunnyvale, CA) were performed with the 40 discrepant samples to confirm the results as false negatives (data not shown). The results were matched to the results of the TMC-PCR assay. To check the false

Table 3 Comparison of results of MGB/CLP (TMC-PCR) and TAMRA/NonCLP real time RT-PCR (TTN-PCR) in different types of specimens

\begin{tabular}{|c|c|c|c|c|c|c|c|c|c|}
\hline & & \multicolumn{8}{|c|}{ TTN-PCR ${ }^{a}$} \\
\hline & & \multicolumn{2}{|c|}{$\begin{array}{c}\text { CSF } \\
(n=102)\end{array}$} & \multicolumn{2}{|c|}{$\begin{array}{c}\text { Stool } \\
(n=48)\end{array}$} & \multicolumn{2}{|c|}{$\begin{array}{l}\text { Throat swab } \\
(\mathrm{n}=8)\end{array}$} & \multicolumn{2}{|c|}{$\begin{array}{l}\text { All specimens } \\
\quad(n=158)\end{array}$} \\
\hline & & + & - & + & - & + & - & + & - \\
\hline \multirow[t]{3}{*}{$\mathrm{TMC}^{-P C R^{b}}$} & + & 29 & 33 & 29 & 7 & 2 & 0 & 60 & 40 \\
\hline & - & 0 & 40 & 0 & 12 & 0 & 6 & 0 & 58 \\
\hline & Totals & 29 & 73 & 29 & 19 & 2 & 6 & 60 & 98 \\
\hline
\end{tabular}

${ }^{a}$ TAMRA/NonCLP real time RT-PCR assay

${ }^{b} \mathrm{MGB} / \mathrm{CLP}$ real time RT-PCR assay. 
positive results, we also performed GeneXpert Enterovirus Assay (GXEA) with positive samples from TMCPCR assay. There were no discord results between TMC-PCR and GXEA (data not shown).

The differences in viral titer were compared to the $\mathrm{Ct}$ mean values of CSF-positive results. The $\mathrm{Ct}$ mean values from TMC-PCR and TTN-PCR of positive CSF specimens were 34.84 and 32.82 , respectively. The TTN-PCR was lower than TMC-PCR in terms of the absolute value of $\mathrm{Ct}$, but the rate of positive TMC-PCR was higher than in the TMC-PCR assay. The results in stool specimens showed the same pattern, despite the absolute mean value of $\mathrm{Ct}$ differed between TMC-PCR (30.19) and TTN-PCR (28.91). Although TMC-PCR assay has better sensitivity compared with TTN-PCR assay, the Ct vale of TMC-PCR assay in certain sample is higher than that of TNC-PCR assay. The $\mathrm{Ct}$ value is not only factor to determine the sensitivity. In our results, TMC-PCR assay has slightly higher Ct than TTN-PCR assay but very lower standard deviation (SD) compared with TTN-PCR assay in low viral titers at inter assay (Table 1). It means that TMC-PCR assay can produce stable diagnostic result in the specimen with low viral titers such as CSF. We can confirm the high sensitivity in the low titer proficiency sample in the Table 2 based on stability induced by CLP and MGB technologies. For example in the Table 2, TMC-PCR assay produced a positive result, whereas TTN-PCR assay produced a negative result at a 10-fold lower viral titer than the panel: CVB3 (EV07-07 vs. EV07-12), E11 (EV07-03 vs. EV07-04) and E30 (EV07-08 vs. EV07-09). We also evaluate the sensitivity of assay developed in this study using clinical samples and confirm the high sensitivity of TMCPCR assay $(62 / 73)$ in the CSF sample than TTN-PCR assay (29/73). Conclusively TMC-PCR assay has slightly higher $\mathrm{Ct}$ value in the certain sample with high purity (culture supernatant or pure gene serial diluents), but can produce stable diagnostic results at the clinical sample with low viral titers.

The results reported that the TMC-PCR assay is a better routine diagnostic method for EV meningitis, because of the low quantities of viral RNA in CSF specimens, not only rapid and accurate results, and may be a useful molecular screening method.

\section{Conclusion}

This study revealed that TMC-PCR assay could give reliable results and showed better reproducibility for routine laboratory diagnosis. Also technical modification of primer provided to increase sensitivity. Our data suggest that TMC-PCR assay may be more suitable to routine diagnostic assay for EV detection from clinical specimens even though TMC-PCR assay was not the novel real-time RT-PCR assay.
List of Abbreviations

(EV): Enterovirus; (E): Echovirus; (CSF): cerebrospinal fluid; (CVA): coxsackievirus $A$; (CVB): coxsackievirus $B$.

\section{Acknowledgements}

This study was supported by an intramural research fund from the National Institute of Health, Korea.

\section{Author details}

${ }^{1}$ Division of Enteric and Hepatitis Viruses, Center for Infectious Diseases, National Institute of Health, Korea Center for Disease Control and Prevention, Chungcheongbuk-do, 363-951, Korea. ${ }^{2}$ Department of Pediatrics, Catholic University College of Medicine, Suwon, 445-744, Korea. ${ }^{3}$ Department of Laboratory Animal Medicine, College of Veterinary Medicine, Seoul National University, Seoul, 151-742, Korea. ${ }^{4}$ Department of Biology, College of Sciences, Kyung Hee University, Seoul, 130-701, Korea.

\section{Authors' contributions}

$J Y H, A Y K, J H A$ and SYH performed genome analysis and cell culture. JHK and JHP drafted the manuscripts. JYH and SHL contributed to collection specimen and clinical diagnosis. JYH, BHK and DSC designed the study and critically revised the manuscript. All of the authors read and approved the final version of the manuscript.

\section{Competing interests}

The authors declare that they have no competing interests.

Received: 29 April 2011 Accepted: 29 June 2011

Published: 29 June 2011

\section{References}

1. Berlin LE, Rorabaugh ML, Heldrich F, Roberts K, Doran T, Modlin JF: Aseptic meningitis in infants $<2$ years of age: diagnosis and etiology. $J$ Infect Dis 1933, 168:888-892.

2. Rotbart HA: Enteroviral infections of the central nervous system. Clin Infect Dis 1995, 20:971-981.

3. Abzug MJ, Levin MJ, Rotbart HA: Profile of enterovirus disease in the first two weeks of life. Pediatr Infect Dis J 1993, 12:820-824.

4. Modlin JF: Perinatal echovirus infection: insights from a literature review of 61 cases of serious infection and 16 outbreaks in nurseries. Rev Infect Dis 1986, 8:918-926.

5. Oberste MS, Michele SM, Maher K, Schnurr D, Cisterna D, Junttila N, Uddin M, Chomel JJ, Lau CS, Ridha W, al-Busaidy S, Norder H, Magnius LO, Pallansch MA: Molecular identification and characterization of two proposed new enterovirus serotypes, EV74 and EV75. J Gen Virol 2004, 85:3205-3212.

6. Tu PV, Thao NT, Perera D, Huu TK, Tien NT, Thuong TC, How OM, Cardosa MJ, McMinn PC: Epidemiologic and virologic investigation of hand, foot, and mouth disease, southern Vietnam, 2005. Emerg Infect Dis 2007, 13(11):1733-1741.

7. Chapman NM, Tracy S, Gauntt CJ, Fortmueller U: Molecular detection and identification of EV using enzymatic amplification and nucleric acid hybridization. J Clin Microbiol 1990, 28:843-850.

8. Halonen P, Rocha E, Hierholzer J, Holloway B, Hyypiä T, Hurskainen P, Pallansch M: Detection of enterovirus and rhinoviruese in clinical specimens by PCR and liquid-phase hybridization. J Clin Microbiol 1995, 33:648-653.

9. Watkins T, Woegerbauer M, Hollemann D, Hufnagl P: Rapid diagnosis of enterovirus infections by real-time PCR on the Light Cycler using the TaqMan format. Diag Microbiol Infect Dis 2002, 42:99-105.

10. Chonmaitree T, Ford C, Sanders C, Lucia HL: Comparison of cell cultures for rapid isolation of enterovirus. J Clin Microbiol 1988, 26:2576-80.

11. Mamilton MS, Jackson MA, Abel D: Clinical Utility of polymerase chain reaction testing for enteroviral meningitis. Pediatr Infect Dis J 1999, 18:533-537.

12. Rotbart HA: Diagnosis of enteroviral meningitis with the polymerase chain reaction. J Pediatr 1990, 117:85-89.

13. Tanel RE, Kao SY, Niemiec TM, Loeffelholz MJ, Holland DT, Shoaf LA, Stucky ER, Burns JC: Prospective comparison of culture vs genome detection for diagnosis of enteroviral meningitis in childhood. Arch Pediatr Adolesc Med 1996, 150:919-924. 
14. Schmidt NJ, Lennette EH, Ho HH: Comparative sensitivity of human fetal diploid kidney cell strains and monkey kidney cell cultures for isolation of certain human viruses. Am J Clin Pathol 1965, 43:297-301.

15. Andréoletti L, Blassel-Damman N, Dewilde A, Vallée L, Cremer R, Hober D, Wattré P: Comparison of use cerebrospinal fluid, serunm, and throat swab specimens in diagnosis of enteroviral acute neurological infection by rapid RNA detection PCR assay. J Clin Microbiol 1998, 36:589-591.

16. Hymas WC, Aldous WK, Taggart EW, Stevenson JB, Hillyard DR: Description and validation of a novel real-time RT-PCR enterovirus assay. Clin Chem 2008, 54:406-413.

17. Kessler HH, Santner B, Rabenau H, Berger A, Vince A, Lewinski C, Weber B, Pierer K, Stuenzner D, Marth E, Doerr HW: Rapid diagnosis of enterovirus infection by a new one-step reverse transcription-PCR assay. J Clin Microbiol 1997, 35:976-977.

18. Corless CE, Guiver M, Borrow R, Edwards-Jones V, Fox AJ, Kaczmarski EB, Mutton KJ: Development and evaluation of a real-time RT-PCR for the detection of enterovirus and parechovirus RNA in CSF and throat swab samples. J Med Virol 2002, 167:555-562.

19. Dierssen U, Rehren F, Henke-Gendo C, Harste G, Heim A: Rapid routine detection of enterovirus RNA in cerebrospinal fluid by a one-step realtime RT-PCR assay. J Clin Virol 2008, 42:58-64.

20. Mohamed N, Elfaitouri A, Fohlman J, Friman G, Blomberg J: A sensitive and quantitative single-tube real-time reverse transcriptase-PCR for detection of enteroviral RNA. J Clin Virol 2004, 30(2):150-156.

21. Petitjan J, Vabet A, Dina J, Gouarin S, Freymuth F: Development and evaluation of a real-time RT-PCR assay on the LightCycler for rapid detection of enterovirus in cerebrospinal fluid specimen. J Clin Virol 2006, 35:278-284.

22. Verstrepen WA, Bruynseels $P$, Mertens AH: Evaluation of a rapid real-time RT-PCR assay for detection of enterovirus RNA in cerebrospinal fluid specimens. J Clin Viral 2002, 25(Suppl 1):39-43.

23. Verstrepen WA, Kuhn S, Kockx MM, van de Vyvere ME, Martens AH: Rapid detection of enterovirus RNA in cerebrospinal fluid specimens with a novel single-tube real-time reverse transcription-PCR assay. J Clin Microbiol 2001, 39:4093-4096.

24. Hong J, Kang B, Kim A, Hwang S, Lee S, Kim J, Lee HY, Kang SH, Cheon DS: Enhanced Detection of Enteroviruses in Clinical Samples by RT-PCR using Complementary Locked Primer Technology. J Clin Microbiol 2010, 48:615-616.

25. Afonina IA, Reed MW, Lusby E, Shishkina IG, Belousov YS: Minor groove binder-conjugated DNA probes for quantitative DNA detection by hybridization-triggered fluorescence. Biotechnique 2002, 32:940-944, 946949.

26. Kutyavin IV, Afonina IA, Mills A, Gorn W, Lukhtanov EA, Belousov ES, Singer MJ, Walburger DK, Lokhov SG, Gall AA, Dempcy R, Reed MW, Meyer RB, Hedgpeth J: 3'-minor groove binder-DNA probes increase sequence specificity at PCR extension temperatures. Nucleic Acids Res 2000, 28:655-661.

27. Cary J: Assays for virus infection. In A practical approach series, virus culture. Edited by: Cann AJ. New York: Oxford University Press; 1999:83-84.

28. Aertsens $M$, De Cannière $P$, Moors $\mathrm{H}$ : Modelling of silica diffusion experiments with ${ }^{32}$ Si in Boom Clay. J Contam Hydrol 2003, 61:117-129.

29. King RL, Lorch SA, Cohen DM, Hodinka RL, Cohn KA, Shah SS: Routine cerebrospinal fluid enterovirus polymerase chain reaction testing reduces hospitalization and antibiotic use for infants 90 days of age or younger. Pediatrics 2007, 120:489-496.

30. Lukhtanov EA, Lokhov SG, Gorn W, Podyminogin MA, Mahoney W: Novel DNA probes with low background and high hybridization-triggered fluorescence. Nucleic Acids Res 2007, 35:e30.

\section{doi:10.1186/1743-422X-8-330}

Cite this article as: Hong et al: Development of a highly sensitive realtime one step RT-PCR combined complementary locked primer technology and conjugated minor groove binder probe. Virology Journal 2011 8:330.

\section{Submit your next manuscript to BioMed Central and take full advantage of:}

- Convenient online submission

- Thorough peer review

- No space constraints or color figure charges

- Immediate publication on acceptance

- Inclusion in PubMed, CAS, Scopus and Google Scholar

- Research which is freely available for redistribution 